\title{
Isolation of Photosystem II Reaction Center Complexes from
}

\section{Plants}

Michael Seibert and Rafael Picorel

\begin{abstract}
Methods to isolate and purify 6- and 5-Chl D1/D2/Cyt $b_{559}$ photosystem II reaction center complexes from plants are presented, and the advantages and disadvantages of each procedure are discussed. One of the simpler 6-Chl procedures and a procedure for isolating 5-Chl complexes are described in detail. Furthermore, a rapid procedure that produces relatively large amounts of less pure 6-Chl material (i.e., more non-pigmented protein) is also described. Criteria to assess the purity of PSII reaction center preparations are presented, and problems associated with each of the isolation procedures are discussed.
\end{abstract}

Key Words: Intrinsic protein, isolation, pigment-protein complex, photosystem II, reaction center, purification, chromatography.

\section{Introduction}

The reaction center (RC) complex of photosystem II (PSII) was first isolated by Nanba and Satoh (1), 19 years after the bacterial reaction center was purified. Both are integral membrane protein complexes, and the latter was the first such complex for which an X-ray crystal structure was obtained (2). The isolation of the PSII RC, containing the D1 and D2 polypeptides and Cyt $\mathrm{b}_{559}$, started a long series of events that have led to many advances in understanding functional 
aspects of PSII and its structure at the molecular level $(3,4)$. Although the isolated PSII RC itself has not been crystallized well enough that a detailed crystal structure could be obtained, X-ray crystal structures of PSII core complexes, which contain the RC, have been obtained for cyanobacteria, though not plants (5-6). Nevertheless, this Chapter will illustrate some of the more common procedures used to isolate the PSII RC from plants and the pitfalls that researchers might face in doing so. The procedures described have been optimized for spinach, pea, and sugar beet.

\section{Materials}

1. Plant leaves such as from spinach (see Note 1), pea, and sugar beet, but modifications of the procedures have worked with wheat and Spirodella.

2. Warring blender and cheesecloth.

3. Cold room or cold box.

4. Preparative centrifuge, centrifuge rotors capable of generating forces of up to $33,000 \mathrm{xg}$, and centrifuge tubes (see Note 2).

5. Spectrophotometer for determining chlorophyll concentrations and absorption spectra.

6. Detergent (Triton X-100 and n-dodecyl- $\beta$-D-maltoside ( $\beta$-DM)), buffers, sucrose, and common salts.

7. Anion-exchange resin, TSK-GEL Toyopearl DEAE 650(S) (see Note 3).

8. Chromatographic columns $(2.5 \times 9 \mathrm{~cm}, 1.6 \times 10 \mathrm{~cm}$, and $1 \times 10 \mathrm{~cm})$. 
9. Pumps and fraction collector or an FPLC.

10. Linear gradient maker.

11. Dialysis tubing.

12. Centricon or Centriprep centrifugal concentrator tubes.

13. Buffer K-1: $50 \mathrm{mM} \mathrm{Na} / \mathrm{K}$ phosphate (pH 7.4), $100 \mathrm{mM}$ sucrose, and $200 \mathrm{mM} \mathrm{NaCl}$.

14. Buffer K-2: $50 \mathrm{mM} \mathrm{Na} / \mathrm{K}$ phosphate (pH 6.9), $300 \mathrm{mM}$ sucrose, and $50 \mathrm{mM} \mathrm{NaCl}$.

15. Buffer K-3: $40 \mathrm{mM} \mathrm{Na} / \mathrm{K}$ phosphate (pH 6.9).

16. Buffer K-4: $20 \mathrm{mM}$ Mes- $\mathrm{NaOH}$ (pH 6.5), $400 \mathrm{mM}$ sucrose, $15 \mathrm{mM} \mathrm{NaCl}$, and $5 \mathrm{mM} \mathrm{MgCl}$.

17. Buffer A $50 \mathrm{mM}$ Tris- $\mathrm{HCl}(\mathrm{pH} 7.2)$ and $30 \mathrm{mM} \mathrm{NaCl}$.

18. Buffer B: $50 \mathrm{mM}$ Tris- $\mathrm{HCl}(\mathrm{pH} 7.2), 30 \mathrm{mM} \mathrm{NaCl}$, and $0.05 \%(\mathrm{w} / \mathrm{v})$ Triton $\mathrm{X}-100$.

19. Buffer C: $50 \mathrm{mM}$ Tris- $\mathrm{HCl}(\mathrm{pH} 7.2)$ and $0.05 \%(\mathrm{w} / \mathrm{v}) \beta-\mathrm{DM}$.

20. Buffer D: $50 \mathrm{mM}$ MES (pH 6.5) and $30 \mathrm{mM} \mathrm{NaCl}$.

21. Buffer E: $50 \mathrm{mM}$ MES (pH 6.5), $30 \mathrm{mM} \mathrm{NaCl}$, and 1\% (w/v) Triton X-100.

22. Buffer F: $50 \mathrm{mM}$ MES (pH 6.5) and 0.05\% (w/v) Triton X-100.

23. Buffer G: $50 \mathrm{mM}$ MES (pH 6.5) and 0.05\% (w/v) $\beta$-DM. 
24. Buffer H: $50 \mathrm{mM} \mathrm{Na}_{2} \mathrm{HPO}_{4}$ (pH 6.5), $50 \mathrm{mM} \mathrm{NaCl}, 0.2 \%$ (w/v) Triton $\mathrm{X}-100$ and $1.2 \mathrm{mM} \beta$ DM.

22. Buffer I: $50 \mathrm{mM}$ MES (pH 6.5), $5 \mathrm{mM}$ imidazol, and $2 \mathrm{mM} \beta$-DM.

\section{Methods}

The methods outlined below describe how to:

1. Isolate PSII membrane fragments, which are required for isolating and purifying PSII RC material,

2. Isolate standard 6-chlorophyll (Chl) per center (2 pheophytins) PSII RC preparations using anionic-exchange chromatography,

3. Isolate 5-Chl per RC preparations using immobilized metal affinity chromatography (IMAC), and,

4. Determine the purity of the preparations.

In addition to step 2 above, a procedure will also be described to rapidly isolate large amounts of 6-Chl-type preparations when the presence of non-pigmented protein contaminants in the RCs is not a major issue.

\subsection{Isolation of PSII Reaction Center Complexes}

Isolated PSII membranes fragments are the starting material for the further isolation and purification of PSII RC material. In 1981 and 1982, three groups reported the use of different 
detergent-solubilization procedures to isolate active PSII membranes (i.e., membranes that still exhibited water-splitting function) from broken thylakoid preparations (7-9). Dunahay et al (10) reported a detailed comparison of the purity of the different types of PSII membrane fragments. It is important for the purpose of the RC-isolation protocols that the PSII membranes are not contaminated with photosystem I (PSI), because PSI complexes if present can under some conditions elute with the PSII RC complex. See the Chapter by Yasusi Yamamoto for more information about the preparation of PSII membrane fragments. The following protocol is used in our laboratories, and it is a slight modification of the so-called KM procedure $(8,10)$. However, the BBY procedure $(7,10)$ can also be used.

\subsubsection{Procedure for Isolating PSII Membrane Fragments}

1. The following steps should be carried out at $4^{\circ} \mathrm{C}$ in dim room light (steps 2-3) and in the dark (steps 4-11). The buffers referred to in this section, and those below, are described in Section 2, Materials.

2. In a Warring blender grind $1 \mathrm{Kg}$ of de-ribbed spinach in ice-cold $\mathrm{K}-1$ buffer $(1: 2 \mathrm{w} / \mathrm{v})$. Repeat 4-5 times for 10 seconds each time with about 30 seconds in between each grind until the green suspension does not contain leaf debris larger than a few millimeters on a side. Filter the suspension through 16 layers of cheesecloth.

3. Centrifuge the filtrate at $500 \mathrm{x}$ g (e.g., 2,000 rpm in a Beckman JLA-10.500 rotor) for $1 \mathrm{~min}$ to remove any cell debris that passes through the cheesecloth.

4. Pour the supernatant into appropriate sized centrifuge tubes and pellet at $12,300 \mathrm{x} g$ (e.g., $10,000 \mathrm{rpm}$ in a Beckman JLA-10.500 rotor) for $25 \mathrm{~min}$. 
5. Discard the supernatant (it contains free Chl, cell cytoplasmic material, proteases, etc.), resuspend the pellet in a smaller volume fresh $\mathrm{K}-1$ buffer with a paint brush, pour into centrifuge tubes, and pellet at 12,300 x g (e.g., 10,000 rpm in a Beckman JLA-10.500 rotor) for $25 \mathrm{~min}$.

6. Resuspend the pellet in K-2 buffer first with a paint brush and then with a homogenizer and run a $\mathrm{Chl}$ analysis. Adjust the suspension to around $3.5 \mathrm{mg} \mathrm{Chl} / \mathrm{ml}$. The $\mathrm{Chl} \mathrm{a/b}$ ratio should be around 2.8-3.0, if the procedure is successful at this point.

7. Add $20 \%(\mathrm{w} / \mathrm{v})$ Triton $\mathrm{X}-100$ to the suspension with gentle stirring to a final ratio of $25: 1$ (w/w) Triton/Chl (see Note 1). Incubate with gentle stirring for $7 \mathrm{~min}$ in the cold. The suspension should turn a deeper shade of green.

8. Pour the suspension into clean centrifuge tubes and pellet at $32,900 \mathrm{x}$ g (e.g., 20,000 rpm in a Beckman JA-25.50 rotor) for $15 \mathrm{~min}$.

9. Discard the supernatant, resuspend the pellet in K-3 buffer first with a paint brush and then with a homogenizer, and pellet at $737 \mathrm{x} \mathrm{g}$ (e.g., 3,000 rpm in a Beckman JA-25.50 rotor) for $1.5 \mathrm{~min}$ to remove starch.

10. Pour the supernatant into clean centrifuge tube and pellet at $32,900 \mathrm{x}$ g (e.g., 20,000 rpm in a Beckman JA-25.50 rotor) for $15 \mathrm{~min}$.

11. Resuspend the pellet in K-4 first with a paint brush and then with a homogenizer and run a $\mathrm{Chl}$ analysis. A $\mathrm{Chl} \mathrm{a} / \mathrm{b}$ ratio of 1.8-2.2 indicates a successful preparation at this point. The 
membranes can be stored at $-80^{\circ} \mathrm{C}$ in the freezer or under liquid $\mathrm{N}_{2}$ for up to one year until use.

\subsubsection{Procedures for Isolating and Purifying 6-Chl PSII Reaction Center Complex}

This procedure is based on the original by Nanba and Satoh (1), which produced highly labile material $(\mathbf{1 1 , 1 2})$. Stabilization of the material was accomplished by exchanging the non-ionic detergent $\beta$-DM (or lauryl maltoside) for the non-ionic detergent Triton $\mathrm{X}-100(\mathbf{1 1 , 1 3 )}$. However, even after purification and stabilization, if the material is to be left unfrozen in room light for more than a few minutes, the researcher should work at $4{ }^{\circ} \mathrm{C}$ and an oxygen-scrubbing system added to the material (13).

\subsubsection{Standard Procedure for Preparing Highly Purified RCs (0.05\% Triton X-100)}

This protocol produces a highly purified PSII RC preparation, but it can take up to several days to complete (around $72 \mathrm{~h}$ with the starting material suggested below; see Note 4), depending on how much material is to be isolated.

The following steps should be carried out at $4^{\circ} \mathrm{C}$ in the dark:

1. The following steps should be carried out at $4^{\circ} \mathrm{C}$ in the dark.

2. Unfreeze $62 \mathrm{mg} \mathrm{Chl}$ of PSII-enriched membrane fragments and pellet at 32,900 x g (e.g., 20,000 rpm in a Beckman JA-25.50 rotor) for $15 \mathrm{~min}$.

3. Resuspend the pellet in $48 \mathrm{ml}$ (final volume) of buffer $\mathrm{A}$.

4. Add $12 \mathrm{ml} \mathrm{20 \% (w/v)} \mathrm{Triton} \mathrm{X-100} \mathrm{(60} \mathrm{ml}$ total final volume at $1 \mathrm{mg} \mathrm{Chl} / \mathrm{ml}$ and 4\% w/v Triton) slowly with gentle stirring and incubate for $1 \mathrm{~h}$ also with gentle stirring. 
5. Centrifuge at $32,900 \mathrm{xg}$ for $1 \mathrm{~h}$ and keep the supernatant.

6. Load the supernatant onto a pre-packed $\left(4^{\circ} \mathrm{C}\right)$ TSK-GEL Toyopearl DEAE 650(S) anion exchange column $(1.6 \times 10 \mathrm{~cm})$ that had been pre-equilibrated with buffer B.

7. Wash the column overnight with the same buffer at a flow rate of $2.5 \mathrm{ml} / \mathrm{min}$ until the eluate exhibits a 417:435 $\mathrm{nm}$ peak ratio of about 1.16 (this ratio is approximately the ratio of the final RCs as purified). This ratio is a better measure of final purity than the absorbance of the eluate at $670 \mathrm{~nm}$, which depends on the column flow rate. The wash step takes about $30 \mathrm{~h}$. Higher amounts of starting material will take longer periods of time to wash.

8. Exchange $\beta$-DM for Triton-X100 by washing the column with the same buffer except with $0.1 \%(\mathrm{w} / \mathrm{v}) \beta$-DM substituted for the Triton. Continue to wash until the absorption band at $280 \mathrm{~nm}$ (residual Triton) has an absorbance lower that 0.1 (1-cm path).

9. Apply $140 \mathrm{ml}$ of a $30-200 \mathrm{mM} \mathrm{NaCl}$ linear gradient (in the same buffer and detergent) at a flow rate of $1 \mathrm{ml} / \mathrm{min}$. Collect $3 \mathrm{ml}$ fractions of the eluate and save. The green band containing the RC complex elutes at 90-120 mM salt. Note that two peaks may come off the column, but the second is much smaller than the first. If so use the peak that comes off first since it is purer (see Note 5).

10. Take the absorption spectrum of each fraction, combine those with a red-peak maxima at 675 $\mathrm{nm}$ or higher, and desalt by dialyzing against buffer $\mathrm{C}$ for $1 \mathrm{~h}$ with one buffer exchange. Desalting is required if the samples are to be used for low temperature spectroscopy since high salt will interfere with the formation of a clear glass.

11. If desired, the material can be concentrated using Centriprep YM-50 centrifugal filter devices (50,000 MW cut-off; Amicon Bioseparations, Bedford, MA) or Centricon-50 (50,000 MW cut-off, Amicon, Beverely, MA) concentrators, if small volumes are to be concentrated. 
When the desired concentration is achieved, freeze the sample in liquid $\mathrm{N}_{2}$ and store under liquid $\mathrm{N}_{2}$. The samples can also be stored at $-80^{\circ} \mathrm{C}$ in a freezer if they are to be used within a short period of time or on dry ice if they are to be shipped.

3.1.2.2. Modified Procedure for Faster Preparation of RCs with High Yield but with some nonpigmented protein contaminants (1\% Triton $X-100)$

This procedure can be used if large amounts of material are needed, and contamination from non-pigmented proteins is not a significant issue. The advantage of this protocol over the one describe above is that the isolation procedure takes much less time (steps 2-12 in Subheading 3.1.2.2 take around $20 \mathrm{~h}$ with the suggested starting material) (see Note 6).

1. The following steps should be carried out at $4{ }^{\circ} \mathrm{C}$ in the dark.

2. Unfreeze $62 \mathrm{mg}$ Chl of PSII-enriched membrane.

3. Centrifuge the suspension at $32,900 \mathrm{x}$ g (e.g., 20,000 rpm in a Beckman JA-25.50 rotor) for $15 \mathrm{~min}$. Resuspend the pellet in buffer D (see Note 7) to a final volume of $48 \mathrm{ml}$.

4. Add $12 \mathrm{ml} \mathrm{20 \% (w/v)} \mathrm{Triton} \mathrm{X-100} \mathrm{(60} \mathrm{ml} \mathrm{total} \mathrm{final} \mathrm{volume} \mathrm{at} 1 \mathrm{mg} \mathrm{Chl} / \mathrm{ml}$ and $4 \% \mathrm{w} / \mathrm{v}$ Triton) slowly with gentle stirring and incubate for $2 \mathrm{~h}$ also with gentle stirring.

5. Pellet at $32,900 \mathrm{xg}$ for $1 \mathrm{~h}$.

6. Load the supernatant onto a TSK-GEL Fractogel DEAE 650(S) column $(2.5 \times 9 \mathrm{~cm})$ that had been pre-equilibrated with buffer E. 
7. Wash the column with the same buffer for $2 \mathrm{~h}$ at a flow rate of $2 \mathrm{ml} / \mathrm{min}$, and then apply 170 $\mathrm{ml}$ of a $60-400 \mathrm{mM} \mathrm{NaCl}$ linear gradient in the same buffer but with $0.05 \%(\mathrm{w} / \mathrm{v})$ Triton $\mathrm{X}$ 100 at a flow rate of $1 \mathrm{ml} / \mathrm{min}$.

8. Pool the $3 \mathrm{ml}$ fractions with a clear $\mathrm{Q}_{\mathrm{x}}$ Pheo band at around $543 \mathrm{~nm}$.

9. Dilute the pooled eluate 8-fold with buffer $\mathrm{F}$ and then load it onto a smaller TSK-GEL Fractogel DEAE 650(S) column $(1.6 \times 2.5 \mathrm{~cm})$ pre-equilibrated with buffer E (see Note 8).

10. Wash the column overnight with the same buffer at a flow rate of $1 \mathrm{ml} / \mathrm{min}$.

11. When the eluate shows a 417:435 nm peak ratio of about 1.16 (the wash step takes about 14 h), exchange $\beta$-DM for Triton X-100 by further washing with $45 \mathrm{ml}$ of the same buffer, but with $0.1 \%(\mathrm{w} / \mathrm{v}) \beta$-DM substituted for the Triton.

12. Elute the RC complex with $140 \mathrm{ml}$ of a $60-350 \mathrm{mM} \mathrm{NaCl}$ linear gradient in the same buffer with $0.1 \% \beta$-DM at a flow rate of $1 \mathrm{ml} / \mathrm{min}$ (the green band elutes at about $170 \mathrm{mM}$ salt).

13. Take the spectra of each $3 \mathrm{ml}$ fraction, combine those with a red-peak maximum at $675 \mathrm{~nm}$ or higher and desalt by dialyzing against buffer $\mathrm{G}$ for $1 \mathrm{~h}$ with one buffer exchange (see Note 9).

14. If desired, the material can be concentrated using Centriprep YM-50 centrifugal filter devices (50,000 MW cut-off; Amicon Bioseparations, Bedford, MA). When the desired concentration is achieved, freeze the sample in liquid $\mathrm{N}_{2}$ and store under liquid $\mathrm{N}_{2}$. The samples can also be stored at $-80^{\circ} \mathrm{C}$ in a freezer, if they are to be used within a short period of time or on dry ice if they are to be shipped. 


\subsubsection{Procedure for Isolating and Purifying 5-Chl PSII Reaction Center Complex}

This procedure was developed by Vacha et al (14). This preparation is directly eluted with $\beta$-DM, but may be less stable than the 6-Chl preparations since one of the proximal Chls is missing. Note that an oxygen-scrubbing system can also be added to this preparation to improve stability. The entire isolation procedure takes $30 \mathrm{~h}$ with the amount of starting material suggested below.

1. The following steps should be carried out at $4{ }^{\circ} \mathrm{C}$ in the dark.

2. Unfreeze $31 \mathrm{mg} \mathrm{Chl}$ of PSII-enriched membrane fragments and treat with $2 \mathrm{M} \mathrm{CaCl}_{2}$ for 10 min with gentle stirring.

3. Centrifuge the suspension at $32,900 \mathrm{x}$ g (e.g., 20,000 rpm in a Beckman JA-25.50 rotor) for $15 \mathrm{~min}$ and resuspend the pellet in $50 \mathrm{mM}$ MES ( $\mathrm{pH}$ 6.5) at a Chl concentration of $2 \mathrm{mg}$ $\mathrm{Chl} / \mathrm{ml}$.

4. Solubilize by adding 1 volume of $30 \%(\mathrm{w} / \mathrm{v})$ Triton $\mathrm{X}-100$ to 3 volumes of treated membranes, and incubate for $2 \mathrm{~h}$ with gentle stirring.

5. Centrifuge at $40,000 \mathrm{x}$ g (e.g., $22,000 \mathrm{rpm}$ in a Beckman JA-25.50 rotor) for $30 \mathrm{~min}$ to remove any non-solubilized material.

6. Load the supernatant onto a $\mathrm{Cu}$ (II) affinity column $(1 \times 10 \mathrm{~cm})$ at a flow rate of $4 \mathrm{ml} / \mathrm{min}$.

The column material is prepared by washing Fast-Flow Chelating Sepharose (Cat. No. 170575-01; Amersham [Pharmacia], Uppsala, Sweden) with distilled water, and then degassing the material under vacuum to remove $\mathrm{O}_{2}$ bubbles that could interfere with the chromatography. At this point the material is packed into the $1 \mathrm{x} 10 \mathrm{~cm}$ column. The column is prepared at room temperature, washed extensively with distilled water and then with $10 \mathrm{ml}$ 
of $0.1 \mathrm{M} \mathrm{CuSO}_{4}$. The excess $\mathrm{Cu}$ is removed by washing the column with $100 \mathrm{ml}$ of distilled water, and finally the column is equilibrated with $50 \mathrm{ml}$ of buffer $\mathrm{H}$ at $4^{\circ} \mathrm{C}$. The use of both detergents seems to improve the stability of the preparation.

7. Wash the loaded column at a flow rate of $2.5 \mathrm{ml} / \mathrm{min}$ with buffer $\mathrm{H}$ until the $417: 435 \mathrm{~nm}$ peak ratio of the eluate is about 1.16 .

8. Elute the column with buffer I at a flow rate of $1 \mathrm{ml} / \mathrm{min}$, and collect $3.0 \mathrm{ml}$ fractions.

9. Take the absorption spectra of each fraction and pool those with a red-peak maximum at 677 nm or higher.

10. If desired, the material can be concentrated using Centriprep YM-50 centrifugal filter devices (50,000 MW cut-off; Amicon Bioseparations, Bedford, MA) or Centricon-50 (50,000 MW cut-off, Amicon, Beverely, MA) concentrators, if small volumes are to be concentrated. When the desired concentration is achieved, freeze the sample in liquid $\mathrm{N}_{2}$ and store under liquid $\mathrm{N}_{2}$. The samples can also be stored at $-80^{\circ} \mathrm{C}$ in a freezer, if they are to be used within a short period of time or on dry ice if they are to be shipped.

\subsection{Purity of the Preparations}

\subsubsection{UV-VIS Absorption Spectra}

Room-temperature absorption spectra of 6-Chl RCs, obtained using either low $(0.05 \% \mathrm{w} / \mathrm{v})$ or high (1\% w/v) Triton X-100 concentration in the column-washing buffers, exhibit a red-band maximum at $675.5 \mathrm{~nm}$ resulting from the $\mathrm{Q}_{\mathrm{y}}$ transition of $\mathrm{Chl}$ and Pheo, a $435 \mathrm{~nm}$ band due to Chl, and a $417 \mathrm{~nm}$ band mainly due to Pheo (but also to the Soret bands of Chl and Cyt $\mathrm{b}_{559}$ ). The distinct band at $543 \mathrm{~nm}$ corresponds to the Pheo $\mathrm{Q}_{\mathrm{x}}$ transition, and the bands between 450 $525 \mathrm{~nm}$ to $\beta$-carotene. The spectrum of a 5 -Chl RC preparation is very similar to that of the 6- 
Chl RC material with the exception that the red-band peak is at $677 \mathrm{~nm}$, and the absorption at around $670 \mathrm{~nm}$ is smaller on a relative basis.

\subsubsection{Pigment Quantitation}

Determination of the Chl $a$, Pheo $a$, and $\beta$-carotene contents in all three PSII RC preparations can be done by spectral analysis of the pigments extracted in $80 \%(\mathrm{v} / \mathrm{v})$ acetone following the method described in (15). The pigments (see Note 10) are extracted at room temperature under dim light, sonicated for $1 \mathrm{~min}$, and centrifuged for $3 \mathrm{~min}$ in a microfuge to remove insoluble material. Complete pigment extraction is assured by repeating the extraction procedure twice and checking that no pigments (except $\mathrm{Cyt} \mathrm{b}_{559}$ ) remain in the pellet. Note that the extract needs to have an optical density of between 0.3 and 0.6 absorption units in the $\mathrm{Q}_{\mathrm{y}}$ absorption region, to accurately calculate the pigment concentrations below from the absorption values found in the lower absorption regions. The following equations are used to determine the pigment concentrations where $c$ and $A$ are given in $\mu \mathrm{M}$ and $\mathrm{cm}^{-1}$, respectively.

$$
\begin{aligned}
& c_{\text {Chl }}=11.577 A_{663}-76.994 A_{535-551}+0.624 A_{480} \\
& C_{\text {Pheo }}=0.020 A_{663}+132.505 A_{535-551}-1.150 A_{480} \\
& c_{\text {Car }}=-0.146 A_{663}-4.054 A_{535-551}+8.311 A_{480}
\end{aligned}
$$

\subsubsection{Polypeptide content determination by SDS-PAGE}

Coomassie Brilliant Blue staining of a gel (SDS-PAGE containing 12.5\% acrylamide) demonstrates that all three types of RCs contain the same polypeptides. The heaviest staining bands are at around 33 and $30 \mathrm{kDa}$, which correspond to $\mathrm{D} 2$ and $\mathrm{D} 1$, respectively, depending on 
the presence of urea in the gel. A weakly staining band at $55-60 \mathrm{kDa}$ corresponds to a crosslinked D1-D2 heterodimer, and the low molecular weight band $(9.5 \mathrm{kDa})$ corresponds to the $\alpha$ subunit of the Cyt $b_{559}$.

\section{Notes}

1. If market spinach is used, we have found that material purchased in Denver between the months of April and October produce good RC material. If spinach is purchased during the winter months, it can be difficult to (a) get membranes unless the Triton/Chl ratio is lowered or (b) separate RC and antenna complexes during RC isolation.

2. The centrifugation times may vary with conditions. The times given are the longest times that we have found necessary.

3. TSK-GEL Toyopearl DEAE $650(\mathrm{~S})$ can be stored at room temperature or at $4{ }^{\circ} \mathrm{C}$; however, it should not be frozen. The user is cautioned that the material is an eye and skin irritant, and it is extremely flammable if dried. Refer to the instructions for preparing the resin prior to packing a column and for regenerating the material after use.

4. Increasing the column flow rate can shorten the time-consuming, column-washing steps (although more buffer will be used), if precautions are taken to be sure that everything online (column, resin, fraction collector, tubing, pumps, for example) has the capability to maintain the higher flow rate. Note that the viscosity of a solution containing detergent is quite dependent on the temperature, and thus, at $4^{\circ} \mathrm{C}$ the viscosity is much higher than that at room temperature where all the chromatography tools and method specifications are normally checked. 
5. Higher levels of the D1-D2 heterodimer band at 55-60 $\mathrm{kDa}$ in the SDS-PAGE indicate a more damaged RC preparation. The ideal situation is a non-detectable level of the heterodimer.

6. The RC preparations obtained with high Triton X-100 concentration $(1 \% \mathrm{w} / \mathrm{v})$ tend to have less $\beta$-carotene content.

7. The use of buffers at $\mathrm{pH} 6.5$ (compared to higher $\mathrm{pHs}$ ) results in a more transparent (less turbid) final preparation of RC.

8. When Taurine at a concentration of $1.5 \%(\mathrm{w} / \mathrm{v})$ is added to the column-washing buffers, the RC-6 Chl preparation obtained with high Triton X-100 concentration ( $1 \% \mathrm{w} / \mathrm{v})$ has less nonpigmented protein contaminant, but the yield of the isolated material is lower.

9. The 6-Chl RC preparation obtained with high Triton $\mathrm{X}-100$ concentration $(1 \% \mathrm{w} / \mathrm{v})$ in the column-washing buffer can be further purified, if necessary, using a sucrose density gradient. To make the gradient, a solution of $50 \mathrm{mM}$ MES, $\mathrm{pH} 6.5,500 \mathrm{mM}$ sucrose, and $0.1 \% \beta$-DM is placed in $10 \mathrm{ml}$ centrifuge tubes. Tubes containing this solution are frozen at $-20^{\circ} \mathrm{C}$ and are then allowed to slowly thaw at $4^{\circ} \mathrm{C}$. This procedure will form a sucrose gradient. The tubes are then loaded with contaminated RC material, placed in a swinging bucket rotor (e.g., a Bechman Ti SW41 rotor), and centrifuged overnight at $35,000 \mathrm{rpm}$ at $4^{\circ} \mathrm{C}$. A major green band appears at the middle of the gradient, and this is the pure RC material. We emphasize that the contaminating material is non-pigmented since the pigment content of the preparation is $6 \mathrm{Chls} / 2$ Pheos before and after the sucrose density step. Any green pigmentation in the pellet appears to be aggregated RC.

10. Recent studies $(\mathbf{1 6 , 1 7})$ reveal differences in the spectroscopy of the pigments associated with P680 in PSII core versus PSII RC preparations due to perhaps structural changes in the 
reaction center accompanied by the loss of $\mathrm{Q}_{\mathrm{A}}$. This observation provides new opportunities for the use of the preparations described in this paper for characterizing the effects of structure on the spectroscopy of the reaction center pigments.

\section{Acknowledgments}

The authors would like to thank all of their current and past collaborators for helping us make good use of the preparations described in this article. This work was supported by the Chemical Sciences, Geosciences, and Biosciences Division, Office of Science, U.S. Department of Energy (MS) and by the MCYT of Spain (Grant BFU2005-04722-C02-01 and AGL2008-00377) to RP.

\section{References}

1. Nanba, O. and Satoh, K. (1987) Isolation of a photosystem II reaction center consisting of D1 and D2 polypeptides and cytochrome $b$-559. PNAS USA 84,109-112.

2. Deisenhofer, J., Epp. O., Miki, K., Huber, R., and Michel H. (1985) Structure of the protein subunits in the photosynthetic reaction center of Rhodopseudomonas viridis at $3 \AA$ resolution. Nature 318, 618-624.

3. Dekker, J. P. and Van Grondelle, R. (2000) Primary charge separation in photosystem II. Photosynth Res 63, 195-208.

4. Diner, B. A. and Rappaport, F. (2002) Structure, dynamics, and energetics of the primary photochemistry of photosystem II of oxygenic photosynthesis. An.n Rev. Plant Biol. 53, 551580. 
5. Kamiya, N. and Shen, J.-R. (2003) Crystal structure of oxygen-evolving photosystem II from Thermosynechococcus vulcanus at $3.7 \AA$ resolution. Proc. Natl. Acad. Sci. USA 100, 981003.

6 Guskov, A., Kern, J., Gabdulkhakov, A., Broser, M., Zouni, A. and Saenger, W. (2009) Cyanobacterial photosystem II at $2.9 \AA$ resolution and the role of quinines, lipids, channels and chloride. Nature Structural Biology 16(2), 334-342.

7. Berthold, D. A., Babcock, G. T., and Yocum, C. F. (1981) A highly resolved, oxygenevolving photosystem II preparation from spinach thylakoid membranes. FEBS Lett. 134, 231-234.

8. Kuwabara, T. and Murata, N. (1982) Inactivation of photosynthetic oxygen evolution and concomitant release of three polypeptides in the photosystem II particles of spinach chloroplasts. Plant Cell Physiol. 23, 533-539.

9. Yamamoto, Y., Doi, M., Tamura, N., and Nishimura, M. (1981) Release of polypeptides from highly active $\mathrm{O}_{2}$-evolving photosystem 2 preparation by Tris treatment. FEBS Lett. 133, 265268.

10. Dunahay, T. G., Staehelin, L. A., Seibert, M., Ogilvie, P. D., and Berg, S. P. (1984) Structural, biochemical and biophysical characterization of four oxygen-evolving photosystem II preparations from spinach. Biochim. Biophys. Acta 764, 179-193.

11. Seibert, M., Picorel, R., Rubin, A. B., and Connolly, J. S. (1988) Spectral, photophysical, and stability properties of isolated photosystem II reaction center. Plant Physiol. 87, 303-306. 
12. Chapman, D. J., Gounaris, D., and Barber, J. (1988) Electron-transport properties of the isolated D1-D2-cytochrome $\mathrm{b}_{559}$ photosystem II reaction center. Biochim. Biophys. Acta 933, 423-431.

13. McTavish, H., Picorel, R., and Seibert, M. (1989) Stabilization of isolated PSII reaction center complex in the dark and in the light using polyethylene glycol and an oxygenscrubbing system. Plant Physiol. 89, 452-456.

14. Vacha, F., Joseph, D. M., Durrant, J. R., Telfer, A., Klug, D. R., Porter, G., and Barber, J. (1995) Photochemistry and spectroscopy of a five-chlorophyll reaction center of photosystem II isolated by using a Cu affinity column. Proc. Natl. Acad. Sci. USA 92, 2929-2933.

15. Eijckelhoff, C. and Dekker J. P. (1997) A routine method to determine the chlorophyll $a$, pheophytin $a$, and $\beta$-catotene contents of isolated photosystem II reaction center complexes. Photosynth. Res. 52, 69-73

16. Hillmann, B., Brettel, K., van Mieghem, F. J. E., Kamlowski, A., Rutherford, A. W., and Schlodder E (1995) Charge recombination in Photosystem II. 2. Transient Absorbance difference spectra and their temperature dependence. Biochemistry 34, 4814-4827.

17. Smith, P.J., Peterson, S., Masters, V. M., Wydrzynski, T., Styring, S., Krausz, E., and Pace, R. J. (2002) Magneto-optical measurements of the pigments in fully active photosystem II core complexes from plants. Biochemistry 41: 1981-1989. 